\title{
Using Microcomputers in an Online Introduction to Horticul- ture Class
}

\author{
Stephanie E. Burnett ${ }^{1, *}$
}

1University of Maine, School of Food and Agriculture; sburnett@maine.edu
${ }^{*}$ Correspondence: sburnett@maine.edu; Tel: 1-207-581-2937

\begin{abstract}
Online courses in horticulture increase the breadth of students who may be able to enroll. However, it is challenging to create hands-on learning experiences in online classes that are valuable for student learning. In an online introduction to horticulture class at the University of Maine, we created a hands-on project that is appropriate for students to work on independently at home. Students built an environmental monitoring system using a relatively inexpensive Raspberry Pi microcomputer and sensors for monitoring environmental factors that impact plant growth with a particular focus on monitoring temperature and humidity. They monitored the growing environment in their homes while growing house plants and used the information from their environmental monitoring system to determine whether their home environment was suitable for growing plants. Students were asked to use a pre-existing computer program in the Python language to monitor the environment. They also learned about how components of the code function and changed some simple parts of the code. A majority of students working on this project felt moderately confident, somewhat more confident, or very confident about their ability to use a Raspberry Pi microcomputer in the future. This project provides students with valuable hands-on experience in building environmental monitoring systems and provides them with a deeper understanding of the impact of the environment on plant growth.
\end{abstract}

Keywords: Raspberry Pi; undergraduate education; distance learning

\section{Introduction}

Enrollment in online classes is increasing; these classes offer some advantages compared to in person classes [1]. They are available to students who are not local or may have difficulty traveling to campus. For example, at the University of Maine, in-state, secondary school students can take online classes for college credit at no cost to them. Online classes also accommodate a variety of schedules since students can complete work asynchronously. In the spring of 2020, at least 1300 universities across the United States shifted to remote or online teaching to create a safer learning environment during the coronavirus (COVID-19) pandemic [2]. This emphasized the importance of fully online classes.

Students taking online classes perform at least as well as their peers taking the in-person version of the course, including those classes with a lab [3]. Students in an introductory horticulture class indicated that assignments were the most useful component in their online class [4]. However, lab activities and hands-on projects can be challenging to create and teach online [5].

Microcomputers such as the Raspberry Pi and Arduino are being used commercially to automate irrigation and are a practical and inexpensive way to monitor the growing environment for plants $[6,7,8]$. Microcomputers are also used in a wide variety of courses to introduce students to computer programming, problem solving, and electronics. The 
Citation: Burnett, S.E. Using Microcomputers in an Online Introduction to Horticulture Class. Horticulturae 2021, 7, x.

https://doi.org/10.3390/xxxxx

Academic Editor: Firstname Lastname

Received: date

Accepted: date

Published: date

Publisher's Note: MDPI stays neutral with regard to jurisdictional claims in published maps and institutional affiliations.

Copyright: (c) 2021 by the authors. Submitted for possible open access publication under the terms and conditions of the Creative Commons Attribution (CC BY) license (https://creativecommons.org/license s/by/4.0/).
Raspberry Pi microcomputer, in particular, was created so that students could gain computer literacy and programming skills using inexpensive equipment they could easily use at home [9]. Students feel more motivated in class when they are using a Raspberry Pi to complete assignments [10]. There are many open source and free resources for educators and students working with microcomputers. Despite the practical applications for microcomputers in horticulture, and the potential to use them in labs or hands-on experiences for online classes, there does not seem to be much training for undergraduates to learn to use these tools.

The objective of this work was to develop a hands-on project in which students use a Raspberry Pi microcomputer and environmental sensors to create an environmental monitoring system at home. This project introduced students to the importance of the environment on plant growth and the use of environmental monitoring in horticulture. This project was created for undergraduate and early college students taking an introduction to horticulture course online.

\section{Materials and Methods}

In the spring of 2021, an environmental monitoring system was developed for use by students in PSE110 (Introduction to Horticulture) at the University of Maine. PSE110 is an online class that meets the general education requirement for basic science at the University of Maine. It is an elective for Environmental Horticulture and Sustainable Agriculture students studying to receive a Bachelor's of Science degree. In spring of 2021, there were forty-seven students in the class: 7 students were majoring or minoring in Environmental Horticulture or Sustainable Agriculture; 7 students were within the College of Natural Sciences, Forestry, and Agriculture, but not Environmental Horticulture or Sustainable Agriculture majors, 8 were in the College of Liberal Arts and Sciences, 7 were in the Maine Business School, 3 were majoring in University Studies, and 3 were in the College of Education. An additional 3 students were non-degree undergraduates taking the course out of general interest. Finally, 9 students were enrolled through the University of Maine Division of Lifelong Learning early college program. These students were attending Maine high schools but taking the course for college credit through the University of Maine.

The environmental monitoring system consisted of a Raspberry Pi 4 desktop kit (Raspberry Pi 4 desktop kit; Cana Kit Corporation, Vancouver, BC), a temperature and humidity sensor (DHT22; Gowoops), a soil moisture and temperature sensor (Stemma I2C Capacative Sensor; Adafruit), and wires needed to connect the soil moisture and temperature sensor to the Raspberry Pi. The Raspberry Pi 4 desktop kit contained a Raspberry Pi (Raspberry Pi 4 Model B; Cana Kit Corporation, North Vancouver, BC), a keyboard, mouse, SD card, a power supply, a case for the Raspberry Pi, and high definition multimedia interface (HDMI) cables to connect peripherals to the Raspberry Pi. It also contained a book introducing students to Raspberry Pi [11]. Students were asked to provide a monitor, which in most cases was a smart television connected to the Raspberry Pi via an HDMI cable. If they did not have a monitor, the University of Maine Hackerspace provided one on loan. The SD card included in the Raspberry Pi 4 kit was formatted to contain the operating system (NOOBS or new out of box operating system) and a short program that students could use to monitor either temperature and relative humidity or soil moisture. The program was written in the Python programming language and was accessible from the desktop environment. Instructions for assembling the hardware and the program for monitoring the environment were modified from available online resources $[12,13]$. The Raspberry Pi 4 kit, sensors, and peripherals (except a monitor) were provided at no cost to all students in the class on loan for the semester.

Students were introduced to projects using the Raspberry Pi with short instructional videos (ranging from approximately 3 to $7 \mathrm{~min}$ ) that were shared through the course learning management system (Brightspace; D2L, Kitchener, Ontario). The first video explained the Raspberry Pi broadly; for example, we explained what general projects you 
could create using the Raspberry $\mathrm{Pi}$, how to set it up to use it as a desktop, and how to navigate the desktop environment. More specifically, students learned how to use the Raspberry Pi kit to create an environmental monitoring system. The environmental monitoring system was simple and provided instantaneous data, but it did not download data to a spreadsheet. We described how to set up the hardware and connect sensors to the Raspberry Pi, and how to run the existing Python code to monitor the environment. Students were not asked to write original Python code, but they were oriented to important components of the program (i.e. loops, variables, etc...). They were also asked to make a small change in the code which changed the time between measurements. The goal of these videos was to provide students with the information needed to understand how you can use a Raspberry Pi generally, and how to use it to connect the temperature and relative humidity and soil moisture sensors to the Raspberry Pi. Supplemental resources provided more information about the Python programming language and how to progress further in creating an environmental monitoring system [11,12,13]

Students completed six assignments in which they were asked to assemble their environmental monitoring system, measure the temperature and humidity in their home, make a small change to the Python program, and determine whether their home growing environment was appropriate for growing a house plant. General guidelines were provided regarding the appropriate temperature and humidity for growing most house plants and more detailed information was provided if students wanted to look up a specific plant [14]. The complexity of the assignments increased as the semester progressed so that students were initially introduced to the concept of microcomputers, then connected the temperature and relative humidity sensor to the Raspberry Pi, then ran a program to monitor the environment and finally changed the program slightly. Measuring the soil moisture and temperature was an optional assignment for students and won't be discussed in detail.

In a typical year, students who are relatively close to campus would be able to access the University of Maine Hackerspace (Hackerspace). This group on campus provides equipment and guidance for students working with Raspberry Pi, 3D printing, Arduino, or other technologies. However, during this project, the Hackerspace was closed due to the COVID-19 pandemic. Students were able to ask questions to the instructor in group office hours sessions dedicated to this project, over email, or by appointment.

At two points in the semester, students were asked to answer a questionnaire related to the Raspberry Pi project. The first questionnaire was sent to students after they completed their second assignment and the second was shared with students after they completed their final assignment (Tables 1 and 2). In the second questionnaire, students were also asked to identify additional resources that would have supported learning in the class and what components they would like to see added to the project.

\section{Results and Discussion}

Table 1. Student comfort with Raspberry Pi after the second assignment.

\begin{tabular}{ccc}
\hline \multicolumn{1}{c}{ Question } & Response & Student Response Rate $^{\mathbf{1}}$ \\
\hline $\begin{array}{c}\text { How would you rate your } \\
\text { comfort with using Rasp- } \\
\text { berry Pi after this project? }\end{array}$ & Very confident & $23.3 \%$ \\
& $\begin{array}{c}\text { Somewhat more confident } \\
\text { than before this project }\end{array}$ & $58.1 \%$ \\
& Moderately confident & $16.3 \%$ \\
& Somewhat less confident & $2.3 \%$ \\
\hline
\end{tabular}


Not very confident at all

$0 \%$

${ }^{1} 43$ students out of 47 enrolled in the class completed this questionnaire (91\%)

Table 2. Student experience and perceived learning related to Raspberry Pi sixth (last) assignment.

\begin{tabular}{|c|c|c|}
\hline Question & Response & Student Response Rate ${ }^{1}$ \\
\hline $\begin{array}{l}\text { Prior to PSE110, did you } \\
\text { have experience using the } \\
\text { Raspberry Pi? }\end{array}$ & $\begin{array}{l}\text { No, this is my first experi- } \\
\text { ence using the Raspberry Pi }\end{array}$ & $100 \%$ \\
\hline $\begin{array}{l}\text { Do you feel that the exercises } \\
\text { improved your confidence in } \\
\text { working with the Raspberry } \\
\text { Pi? }\end{array}$ & Yes & $100 \%$ \\
\hline
\end{tabular}

${ }^{1} 11$ students out of 47 enrolled in the class completed this questionnaire (23\%)

Undergraduate students in introduction to horticulture had no prior experience working with micro-computers, however, this activity increased student confidence in working with a Raspberry Pi in the future (Tables 1 and 2). A majority of students in class (32 out of 47 or $68 \%$; data not shown) completed all six projects related to the Raspberry Pi. This project provides a basic introduction to hardware and computer programming, but it also introduces students to the importance of monitoring the environment when growing plants. Microcomputers, such as the Raspberry Pi, are used to engage students in programming in other fields such as computer science and engineering. However, they are not typically used in horticulture classes despite their practical applications in horticulture $[6,7,8,10]$.

After the second project, a majority of the class (97.7\%) felt either moderately confident, somewhat more confident, or very confident in their ability to use Raspberry Pi (Table 1). Only one student felt somewhat less confident, and none of the students indicated that they didn't feel confident at all in their ability to work with the Raspberry Pi (Table 1). Before beginning to work with the Raspberry Pi, students watched lecture videos related to the benefits of using Raspberry Pi microcomputers, how to set up the Raspberry $\mathrm{Pi}$ as a desktop computer, how to connect a temperature and relative humidity sensor to the Raspberry Pi, and how to run a Python program to monitor those environmental factors. After students successfully set up their temperature and humidity sensor and monitored data, they watched a video describing the Python program and how to change a small component (the measurement frequency). One advantage of having students work on this project in an online class is that they were not limited by time in completing their assignments. Students engaged with videos related to the Raspberry Pi project more frequently than they engaged with the other online video lectures. For example, on average, students viewed lecture videos about once (1.27 times on average for all students viewing the videos; data not shown). But, students usually watched the Raspberry Pi videos about twice (1.89 times on average for all students viewing the video; data not shown). The greatest engagement was with the videos describing how to connect the DHT22 sensor to the Raspberry Pi and how to run the Python program that monitors temperature and relative humidity. Students watched these 2.5 or 2.35 times on average for the hardware and software videos, respectively. Other classes working with Raspberry Pi microcomputers found that students were more likely to complete homework assignments when they are using the Raspberry Pi [10]. 
After the sixth and last project, all of the students indicated that the exercises improved their confidence in using Raspberry Pi microcomputers in the future, and none of the students had prior experience using Raspberry Pi microcomputers (Table 2). At this point in the semester, the students had watched all videos related to using a Raspberry $\mathrm{Pi}$. Those include the videos listed above, but also a short video describing how to make a small change to the python program that changed how frequently the environmental monitoring system measured temperature and relative humidity. After completing all of the projects, students were asked to identify any resources that would have supported them during the project. The primary resource students thought would be helpful is a trouble-shooting document to help them solve problems that other students frequently encountered (Data not shown). We plan to implement this in the future, and students would also have the support of the Hackerspace to help them solve problems.

Students were also asked what components they would like to add to the project in the future. Many students indicated that they would like to work more with the soil moisture sensor, which was an optional project. They also expressed an interest in measuring other environmental variables, such as light levels with the Raspberry Pi (Data not shown). These environmental variables are among those that are commonly measured in commercial or research plant production environments [15].

Connecting and monitoring a soil moisture sensor will be a required project in the future so that students will be exposed to more aspects of plant growth. Working with the soil moisture sensor was optional because some components needed for this project were unavailable until the last month of the semester. The soil moisture sensor included in the kit was relatively inexpensive (\$7.50). It was useful for this project to keep the cost manageable. However, these sensors have some drawbacks. The sensors cannot be calibrated for different soil types; calibration is an important step to relate the voltage measured from capacitance sensors to volumetric water content [16]. They also provide a relative measurement of the soil moisture on a unitless scale. This scale ranges from 200 to 2000 (dry to wet) and is not related to volumetric water content or other common measurements of soil moisture. The biggest drawback of these sensors is that it isn't possible to provide recommendations about soil moisture based on the literature. Although the moisture sensors were not research quality, they can help students to become more aware of whether they are under or over-watering plants. More importantly, they raise their awareness of how critical it is to water plants based on the soil moisture or physiological need, rather than on a schedule. Since there are not many high quality, easy to use, and inexpensive light sensors for the Raspberry Pi, we will not require students to measure this variable in the future. In addition, connecting light sensors to the Raspberry Pi and monitoring light is more complicated compared to monitoring the other environmental variables. However, we would like to work with the Hackerspace to develop a more comprehensive optional project that students can complete with light sensors if they wish to.

One success from this project is that students used the environmental data directly in their assignments related to the Raspberry Pi, but also in unrelated lab assignments where they worked with plants. This was not a requirement, but since the students had access to environmental data collected in their home growing environment, they used that in projects in which they learned to start seeds and grow microgreens at home. Several students were so engaged in the Raspberry Pi project that they completed the optional project with the soil moisture sensor and made additional improvements to the Python code so that the Raspberry Pi could automatically add the data to a spreadsheet.

There were some common roadblocks that students encountered that should be considered in the future. Since the students in this class were relatively unfamiliar with the Raspberry Pi or other microcomputers (Table 2), some of them did not know that the 
Raspberry Pi is a stand-alone independent computer rather than a peripheral that they connect to their personal computer. Another common problem was that some students unplugged the Raspberry Pi from the wall without correctly shutting it down. This can result in erasing or damaging the SD card, which left these students without access to the Python programs needed for this project. We were able to address most questions and problems that students encountered through a group question and answer session held on Zoom or individual office hours sessions dedicated to working with the Raspberry Pi. Students who damaged their SD card were provided with another formatted card through the mail or in person.

There are a wide variety of projects related to programming and automation in horticulture that could be completed using the Raspberry Pi or other microcomputers. For example, students could build a sensor-automated irrigation system for use at home or in campus greenhouses [7]. Alternately, students could build an environmental monitoring system for field or greenhouse plant production to test the system in a more commercial environment [8]. Completing relatively simple tasks, such as building an environmental monitoring system and using it to monitor the environment, could be a bridge to using microcomputers for more complex tasks.

In the future, we plan to film an additional short video describing how to shut down the Raspberry Pi correctly and how the Raspberry Pi is similar to a personal computer. We will also work with the Hackerspace to create additional optional projects or workshops for students who wish to work on this project at a deeper level. All students will benefit from the Hackerspace being open and available to answer questions or help with problems they encounter. We hope to develop a more advanced project using microcomputers for students taking a 400-level course. Hopefully early exposure to these concepts in a 100-leve course will give them confidence to work with microcomputers at a higher level later in their college career.

\section{Conclusions}

Students who used a Raspberry Pi and environmental sensors to build an environmental monitoring system in an online introduction to horticulture course were more confident in their ability to work with a Raspberry Pi in the future. Exposing students to technical concepts early in their career makes it possible for them to do more complex projects involving computer programming or working with hardware in the future. This project also reinforced the importance of understanding a plant's growing environment. We plan to continue this project at the University of Maine, and we look forward to providing more complex optional projects for students to work on independently in the future.

Funding: Raspberry Pi Kits were provided by the Center for Innovation in Teaching and Learning at the University of Maine. This project was also funded by the U.S. Department of Agriculture (USDA) and National Institute of Food and Agriculture (NIFA) Multistate Project (\#ME031901) through the Maine Agriculture \& Forest Experiment Station.

Acknowledgments: The author thanks the Center for Innovation in Teaching and Learning at the University of Maine and Ms. Sheridan Adams who assisted in the creation of this activity and provided Raspberry Pi kits to the students in PSE110, 'Introduction to Horticulture'.

\section{References}


1. Seaman, J.E.; Allen, I.E.; Seaman, J. Grade Increase: Tracking Distance Education in the United States. Babson Survey Research Group, 2018.

2. Smalley, A. Higher education responses to coronavirus (Covid-19): National conference of state legislators. Available online: https://www.ncsl.org/research/education/higher-education-responses-to-coronavirus-covid-19.aspx. (accessed 26 on May, 2021).

3. Reuter, R. Online versus in the classroom: Student success in a hands-on lab class. Amer. J. Distance Education 2009, 23, 151-162.

4. VanDerZanden, A.M.; Woline, T. Student perceptions of an online introductory horticulture course. 2008. NACTA J.2008, 52, 33-37.

5. Wortman, S.E.; Gloeb, E. The sustainable lettuce competition: an online learning activity for teaching the scientific method and sustainability tradeoffs. NACTA J. 2019, 63, 59-66.

6. Million, J.B.; Yeager, T.H. Testing an automated irrigation system based on leaching fraction testing and weather in a container nursery. HortTech. 2019, 29, 114-121.

7. Soranz Ferrarezi, R.; Dove, S.K.; van Iersel, M.W. An automated system for monitoring soil moisture using low-cost open-source microcontrollers. HortTech. 2015, 25, 110-118.

8. Anire, R.B.; Cruz, F.R.G; Agulto, I.C. Environmental wireless sensor network using raspberry Pi 3 for greenhouse monitoring system. 2017IEEE $9^{\text {th }}$ International Conference on Humanoid, Nanotechnology, Information Technology, Communication and Control, Environment and Management (HNICEM) 2017, pp. 1-5.

9. Kolling, M. Educational programming on the Raspberry Pi. Electronics. 2016, 5, 33.

10. Hallak, H.A.; Ibrahim, S.; Low, C.; El Mesalami, A. The impact of incorporating hands-on Raspberry Pi Projects with undergraduate education in boosting students' interest in scientific/engineering majors and encouraging women and minorities to advance their integration in practical fields. Proceedings of 2019 IEEE Learning with MOOCS (LWMOOCS). Milwaukee, WI, USA, 23-25 October 2019; pp. 1-7.

11. Halfacree, G. The Official Raspberry Pi Beginner's Guide: How to Use Your New Computer, $2^{\text {nd }}$ ed.; Raspberry Pi Press. Cambridge, United Kingdom, 2019.

12. DHT11, DHT22, and DHT2303 Sensors: Overview. Adafruit. Available online: https://learn.adafruit.com/dht (accessed on 17 May 2021).

13. Adafruit STEMMA soil moisture sensor - I2C Capacitive Moisture Sensor: Overview. Adafruit. Available online: https://learn.adafruit.com/adafruit-stemma-soil-sensor-i2c-capacitive-moisture-sensor (accessed on 17 May 2021).

14. Growing Indoor Plants with Success. University of Georgia Bulletin 1318. Available online: https://extension.uga.edu/publications/detail.html?number=B1318\&title=Growing\%20Indoor\%20Plants\%20with\%20Success (accessed on 18 May 2021).

15. Both, A.J.; Benjamin, L.; Franklin, J.; Holroyd, G.; Incoll, L.D.; Lefsrud, M.G.; Pitkin, G. Guidelines for measuring and reporting environmental parameters for experiments in greenhouses. Plant Methods 2015, 11, 43.

16. Burnett, S.E.; van Iersel, M.W. Morphology and irrigation efficiency of Gaura lindheimeri grown with capacitance sensor-controlled irrigation. HortScience 2008, 43, 1555-1560. 